\title{
EDUCAÇÃO ETNOMATEMÁTICA NAS ESCOLAS INDÍGENAS KARAJÁ DE XAMBIOÁ
}

\section{ETHNOMATHEMATICS EDUCATION IN SCHOOLS OF INDIGENOUS KARAJÁ XAMBIOÁ}

\author{
Haylla Rodrigues de Aguiar ${ }^{1}$ \\ Universidade Federal do Pará - UFPA \\ ORCID:https://orcid.org/0000-0002-6968-9817 \\ Talal Suleiman Mahmoud ${ }^{2}$ \\ Universidade Federal do Paraná - UFPR \\ ORCID:https://orcid.org/0000-000 3-3198-7453 \\ Elisângela Aparecida Pereira de $\mathrm{Melo}^{3}$ \\ Universidade Federal do Tocantins - UFT \\ ORCID:https://orcid.org/0000-0001-6827-0566
}

\section{RESUMO}

Este trabalho apresenta uma investigação realizada com a comunidade indígena Karajá Xambioá, localizada no município de Santa Fé do Araguaia - TO. Para a coleta dos dados, empregou-se a metodologia etnográfica. Por meio de entrevistas e de observação, diretamente na comunidade, investigou-se o que os indígenas compreendem como educação escolar indígena diferenciada, na perspectiva do ensino intercultural, considerando os aspectos socioculturais dessa comunidade. O objetivo foi o de fazer um estudo investigativo da realidade educacional das escolas indígenas localizadas no território Karajá Xambioá. Foram analisados, entre outros aspectos, a necessidade premente dos professores e da comunidade de desenvolverem, nas escolas da aldeia, um estudo sobre o processo de ensino e aprendizagem que leve em consideração as matemáticas produzidas em seu contexto cultural e social.

Palavras-chave: Interdisciplinaridade. Educação escolar indígena. Formação de professor indígena.

\section{INTRODUÇÃO}

Os povos indígenas do Brasil lutam, atualmente, pela efetivação dos seus direitos educacionais, conquistados por meio das reivindicações do movimento indígena. Esses direitos foram estabelecidos, segundo Brasil (1996), pela Constituição Federal de 1988, pela Lei de Diretrizes e Bases da Educação Nacional (LDB) de 1996 e pelo Plano Nacional de Educação (PNE) de 2001 (Brasil, 2001). Eles representam o

\footnotetext{
${ }^{1}$ Mestranda em Educação Matemática pela Universidade Federal do Pará - UFPA, Campus de Belém PA, Brasil. Contato: rhaylla.rodrigues@gmail.

${ }^{2}$ Professor Doutor do Curso de Licenciatura em Ciências Exatas, da Universidade Federal do Paraná UFPR, Campus Universitário em Pontal do Paraná - CEM - PR, Brasil. Contato: talal@ufpr.br.

${ }^{3}$ Professora Doutora do Curso de Licenciatura em Matemática, da Universidade Federal do Tocantins UFT, Campus Universitário de Araguaína - TO, Brasil. Contato: elisangelamelo@uft.edu.br.
} 
surgimento de uma nova concepção de escola indígena, caracterizada como uma escola comunitária, intercultural, bilíngue/multilíngue, específica e diferenciada.

Toda sociedade produz o próprio conhecimento, de acordo com seu cotidiano e com suas necessidades. Esse conhecimento é gerado em diferentes espaços físicos e geográficos, por diferentes pessoas, de acordo com suas necessidades e perspectivas de vidas futuras.

D’Ambrósio (2005), ao teorizar sobre o Programa de Estudos e Pesquisas em Etnomatemática, considerou os diversos conhecimentos produzidos em diferentes épocas e civilizações por povos indígenas, trabalhadores rurais e urbanos e feirantes. Desse processo de produção, o autor pautou-se no ser humano como feitor e aprendiz do próprio saber e fazer, que chamamos hoje de conhecimento. Assim, “ [...] todo conhecimento é resultado de um longo processo cumulativo de geração, de organização intelectual, de organização sociale de difusão,naturalmentenão dicotômicosentresi” (D’AMBROSIO, 2005, p. 18).

Quando falamos de cultura, a partir dessa conjunção de características, temos que entender e analisar os saberes e as práticas que são produzidos pelas diferentes culturas. Esses métodos de produção ainda são bastante questionados, particularmente, o matemático, que é vivenciado e praticado no cotidiano de pessoas com contexto na diversidade. Esse conhecimento tem distintas formas culturais e crenças no desenvolvimento de seus saberes que, posteriormente, são chamados pelos meios educativos de conhecimentos. Entretanto, alguns ramos das Ciências denominam esses conhecimentos de emergentes, vulgares, sem validade ou do senso comum.

Para abarcar esses saberes, e não, conhecimentos, a Educação Matemática e a Etnomatemática vêm desenvolvendo estudos e pesquisas nos contextos de diversidade cultural. Sobre os conhecimentos advindos das práticas socioculturais, D’Ambrósio (2005, p. 31) assevera:

[...] são o grande motivo do programa de pesquisa, que denomino de Etnomatemática, que tem como um dos objetivos o de procurar entender o saber/fazer matemático ao longo da história da humanidade, contextualizado em diferentes grupos de interesse, comunidade, povos e nações.

Nessa perspectiva, busca, ainda, compreender como os saberem se geram, a fim de que se possam configurar os pressupostos da Etnomatemática, em especial, ao propiciar uma releitura do ensino de Matemática em sala de aula. 
Em geral, o termo "Etnoma temática" está relacionado a conhecimentos presentes nas práticas cotidianas de diferentes grupos. Esses conhecimentos não são isolados: integram-se ao cotidiano, possuindo um aspecto abrangente. Na maioria das vezes, seu uso está aliado à solução de problemas, que é pensada dentro de um conjunto de valores, crenças e saberes que lhe dão significado, não havendo, assim, na resolução desses problemas, uma preocupação disciplinar, pois (MONTEIRO, 2001, p.46).

Esse novo conceito de educação, que está entrelaçado e enraizado no saber tradicional da sociedade em práticas culturais, consolidou-se em agosto de 1984, no V Congresso Internacional de Educação Matemática, em Adelaide - Austrália. De acordo com D’Ambrósio(1996), aEtnomatemáticanãoé uma metodologia de ensino, pois o seu campo de atuação e aprendizagem é muito amplo, porquanto envolve muitos artefatos e mentefatos que foram construídos milenarmente. Assim, é caracterizada como um Programa cuja configuração teórica e prática preconiza que

[...] a abordagem de distintas formas de conhecer é a essência do Orograma Etnomatemática. Na verdade, diferentemente do que sugere o nome, etnomatemática não é apenas o estudo de "matemática das diversas etnias". Para compor a palavra etno matema tica utilizei as raízes tica, matema e etno para significar que há várias maneiras, técnicas, habilidades (tica) de explicar, de entender, de lidar e de conviver (matema) com distintos contextos naturais e socioeconômicosdarealidade(etno)(D’AMBRÓSIO,1996,p.111).

O Programa de Pesquisa em Etnomatemática tem um campo abrangente de pesquisa. Seu objetivo é o de entender o saber/fazer matemático em toda a história da humanidade.

Dentre as distintas maneiras de fazer e de saber, algumas privilegiam comparar, classificar, quantificar, medir, explicar, generalizar, inferir e, de algum modo, avaliar. Falamos então de um saber/fazer matemático na busca de explicações e de maneiras de lidar com o ambiente imediato e remoto. Obviamente, esse saber/fazer matemático é contextualizado e responde a fatores naturais e sociais (D’AMBROSIO,1996,p.22).

Esse saber/fazer é próprio de cada cultura. O conhecimento é motivado de acordo com sua necessidade de responder a situações e a problemas distintos, ou seja, dependentes do seu contexto natural. A Etnomatemática que os povos indígenas vêm desenvolvendo, no caso deste estudo, os Karajá de Xambioá, relaciona-se com as atividades culturais no ambiente escolar, como espaço formativo, e nas salas de aula, de modo a transversalizar o ensino e a aprendizagem dos alunos. Isso ocorre não só na disciplina 'Matemática', mas também nas demais que compõem o currículo. 
Dentre as atividades elucidativas que podemos citar como exemplo dessas ações em sala de aula, tem-se o ensino dos números do povo Iny, que não tem uma representação numérica como as do nosso sistema matemático de símbolos, uma vez que o valor está diretamente ligado à posição que o algarismo ocupa em relação ao número. Devido à necessidade de contar, escrever e quantificar numericamente, os povos indígenas têm um sistema de contagem próprio. Porém podemos dizer que a constituição dos números de matrizes indígenas se trata, a princípio, de um estudo de palavras, e não, de símbolos matemáticos.

O povo Karajá tem um sistema de contagem baseado na quantidade/contagem dos dedos das mãos. Em razão dessa constituição numérica, eles contam todos os dedos das mãos e, quando acabam, contam os dos pés e dizem que uma pessoa vale vinte. Para a matemática escolar, essa contagem tem a base no sistema de contagem de vinte em vinte. De acordo com Ferreira (citando alguns autores),

[...] algumas línguas que utilizam esse sistema, como Karajá (macrojê; Alford, 1987; Karajá, Fortune e Fortune, 1989), rikbaktsá (macrojê; Boswood, 1978), urubu-kaapor (tupi-guarani; Kakumsa, 1988), kadiwéu (guaicuru; Griffiths, 1975), karitiana (arikémm; Landin, 1983) tikuna (isolada; Anderson, 1958), makuxi (karib; Williams, 1932), parecis (aruak; Rowan c.p, 1995) e o dialeto Hohôdene da língua baniwa de Içana (aruak; Aikhenvald c.p, 1995). Rodrigues (1942) descrevem o dialeto kipeá da língua kiriri (macro-jê) também como língua vigesimal (FERREIRA, 2002, p. 260).

Os Iny não tem um significado para os nomes dos números, e seu sistema numérico vai até cem. Ferreira (2002) refere que

[...] todas essas línguas têm palavras distintas para os numerais de um a cinco. Em todas, o termo, para cinco, significa "noss amão", "todos osdedos damão" ou"ofimdamão". Daíparafrente, usa -se a outra mão para contar atédez:"cinco mais um (dedo)", "cinco mais dois" etc. Todos os termos para o numeral dez referem-se às mãos ou aos dedos das mãos. Os sistemas vigesimais dessas línguas são quinários, pois os numerais maiores do que cinco compõem-se dos mesmos cinco termos, eonumeraldezé consideradoacombinaçãode "cinco maiscinco"(mãomaismão)(FERREIRA,2002,p.261).

O sistema numérico até vinte é representado assim: inatxi, inatão, inaubiòwa, iruure, debò-ò sòhòji, debò-ò inatxi, debò-ò inatã̃, debò-ò iruure, debò-ò inaubiowa, debò-ò sòhòji ròhòremy, debò-ò inatxi ròhòremy, debò-ò inatã̃ ròhòremy, debò-ò inaubiòwa, debò-ò ituemy, waa sóhóji, waa inatxi, waa inataõ, waa inaubiwa, waa 
irrure, waa sòhòji ròhòremy, waa inatxi ròhòremy, waa inataõ ròhòremy, waa inaubiowamy ròhòremy, waa ituemy.

O saber matemático desse povo está presente em seu cotidiano e é o suficiente para suprir suas necessidades diárias no interior das aldeias. É tão importante quanto a matemáticadobranco(nãoindígena).D’Ambrósio(1996)refor ça essa aprendizagem e vivência etnomatemática em contextos indígenas, ao referir que

[...] a etnomatemática do indígena serve, é eficiente e adequada para muitas coisas - de fato muito importante - e não há por que substituíla. A etnomatemática do branco serve para outras coisas igualmente muito importantes e não há como ignorá-la. Pretender que uma seja mais eficiente, mais rigorosa, enfim melhor que a outra é, se removida docontexto, umaquestãofalsaefalsificadora(D’AMBROSIO, 1996, p. 118).

Em estudos futuros, será preciso fazer atividades teóricas e práticas com os professores e os demais indígenas. Desse modo, será possível reorientar o ensino e a aprendizagem da matemática escolar, por meio de atividades investigativas na cultura, para que a escola indígena seja, de fato, diferenciada, intercultural, bilíngue e com diferentes formas de se aprender matemática.

Com essa intenção, visamos teorizar e discutir sobre as contribuições que o Programa de Pesquisa Etnomatemática (PPE) proporcionou quando foi apresentado como proposta de ação pedagógica, devido às diretrizes que adotou ao longo dos anos. Discutimos também sobre como o PPE é abordado hoje, sob a ótica de uma educação multicultural, que sofre com as consequências da globalização, dos meios tecnológicos e de informações referenciais no campo teórico da pesquisa e da etnomatemática.

Nosso objetivo é de descrever o contexto cultural e histórico do povo indígena Karajá de Xambioá, localizado no município de Santa Fé - estado do Tocantins - em âmbito educacional. Essa descrição se baseia em relatos orais realizados nos contextos das aldeias desse povo, em especial, com os professores e outros indígenas, que nos deram informações acerca da educação escolar, das práticas socioculturais, da organização social e comunitária, dos modos de sustentabilidade, dos hábitos alimentares, dentre outras que compõem o corpus analisado neste texto.

Nesse novo entendimento, em que a escola indígena vem sendo conceituada e implementada nos últimos anos, a educação escolar indígena não deve ser pensada fora dos contextos próprios de cada comunidade. Por essa razão, esse trabalho se refere a 
questões fundamentais sobre Educação Matemática entre povos de culturas distintas, nesse caso, os grupos indígenas, particularmente, os Karajá de Xambioá.

\section{CONTEXTO DA PESQUISA - O POVO KARAJÁ INY}

O povo Karajá subdivide-se em três grupos: os Karajá, os Javaé e os Karajá de Xambioá. Todos são habitantes das margens dos rios Araguaia e Javaé, embora estejam emestadosdistintos, “ [...] às margens do Araguaia em quatro estados: Goiás, Tocantins, Mato Grosso e Pará. A maior parte de sua população concentra-se na Ilha do Bananal, noParque IndígenadoAraguaia" (TORAL, 1992, p. 17). Vejamos, no mapa abaixo, a localização desses três povos, que foram divididos depois de terem contato com o não indígena.

Figura 1: Mapa das terras indígenas do estado do Tocantins

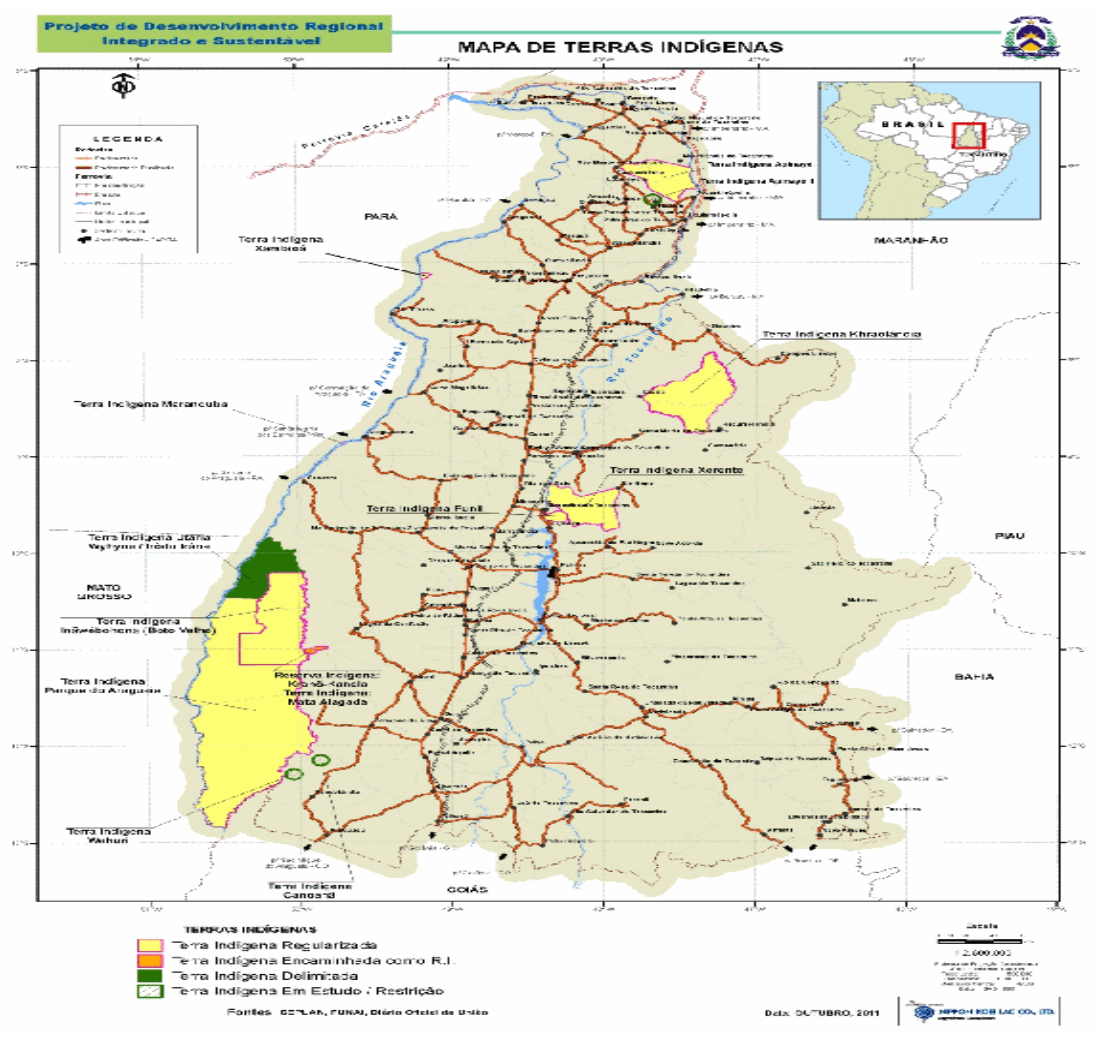

Fonte: http://dc205.4shared.com/doc/tn_9zaS6/preview.html. Acesso em 15 de dez. de 2014

Esse povo compartilha uma tradição mítica que envolve toda a comunidade, que vai desde os rituais de passagem das diferentes fases e ciclos de vida dos seus indivíduos até os mitos de origem, como o xamanismo, os rituais de casamento, o poder político, a relação de parentesco, a pintura corporal, a confecção dos artesanatos de barro branco etc. Essas manifestações fazem desse povo os criadores próprios de 
cultura, em constante processo de afirmação e de troca de conhecimento com o outro. Nesse sentido, Toral (1992), considera que

[...] todos os grupos Karajá vieram do norte. O seu movimento na superfície da terra em que vivem, desde que miticamente saíram das profundezas, é descrito como sendo continuamente orientado para o "alto", ibòòo, i.é., para o sul, para o alto curso do Araguaia. Esse movimento em direção ao alto curso do rio fez-se provavelmente a partir de um ponto original de dispersão situado, ao que tudo indica, no baixo Araguaia, provavelmente próximo à sua foz no Tocantins (TORAL, 1992, p. 16).

$\mathrm{O}$ povo Iny se autodenomina de o povo das águas, devido ao mito de sua criação. Segundo a tradição, eles teriam vindo das profundezas das águas quentes do rio Araguaia. Os anciãos das aldeias Karajá de Xambioá contam que todos os indígenas Karajás viviam juntos, debaixo da terra, ou seja, sob as águas. Nesse lugar, não havia mortes, doenças, fome ou guerras. Certo dia, em sua caminhada, um indígena encontrou uma passagem entre as águas quentes que corriam para cima. Ele ultrapassou a tal passagem e admirou-se com o que viu do lado de fora das águas. Ao regressar para junto da tribo, contou aos parentes o que viu, e todos se encantaram com sua história. Por causa disso, as águas se revoltaram e provocaram um grande redemoinho, fazendo com que os indígenas saíssem do fundo rio e emergissem para as margens do rio Araguaia. Entretanto, nem todos conseguiram passar. Um Koboi (índio gordo) não conseguiu, porque o redemoinho já estava perdendo a força. Seu corpo fechou a passagem e impediu que outros parentes também passassem. Eles ficaram para trás e acredita-se que estejam vivendo sob as águas até hoje. É por isso que o grupo tem suas aldeias à beira do rio Araguaia, margeando seu percurso.

No princípio, os três grupos Karajá viviam juntos, reunidos às margens do baixo Araguaia, e formavam um só povo. Entretanto, essas informações são insuficientes para que possamos afirmar a real localização da moradia primitiva. Dados relatam que os Karajá habitavam o sul do estado do Tocantins no Século XVI. "Tudoisso,noentanto, são reconstituições feitas com bases históricas muito fracas, como as fontes do Século XVII"(TORAL, 1992,p. 17). Assim, o povo Iny habita toda a Ilha do Bananal, cuja localização é apresentada no mapa abaixo. ${ }^{4}$

\footnotetext{
${ }^{4}$ A Ilha do Bananal, localizada no estado do Tocantins, é famosa por ser a maior ilha fluvial do mundo, com uma área de, aproximadamente, $25.000 \mathrm{~km}^{2}$, acesso em abr. de 2015. http://www.mundoeducacao.com/geografia/ilha-bananal.htm
} 
Fonte 2: Mapa da terra indígena na Ilha do Bananal

Localização da llha do Bananal no

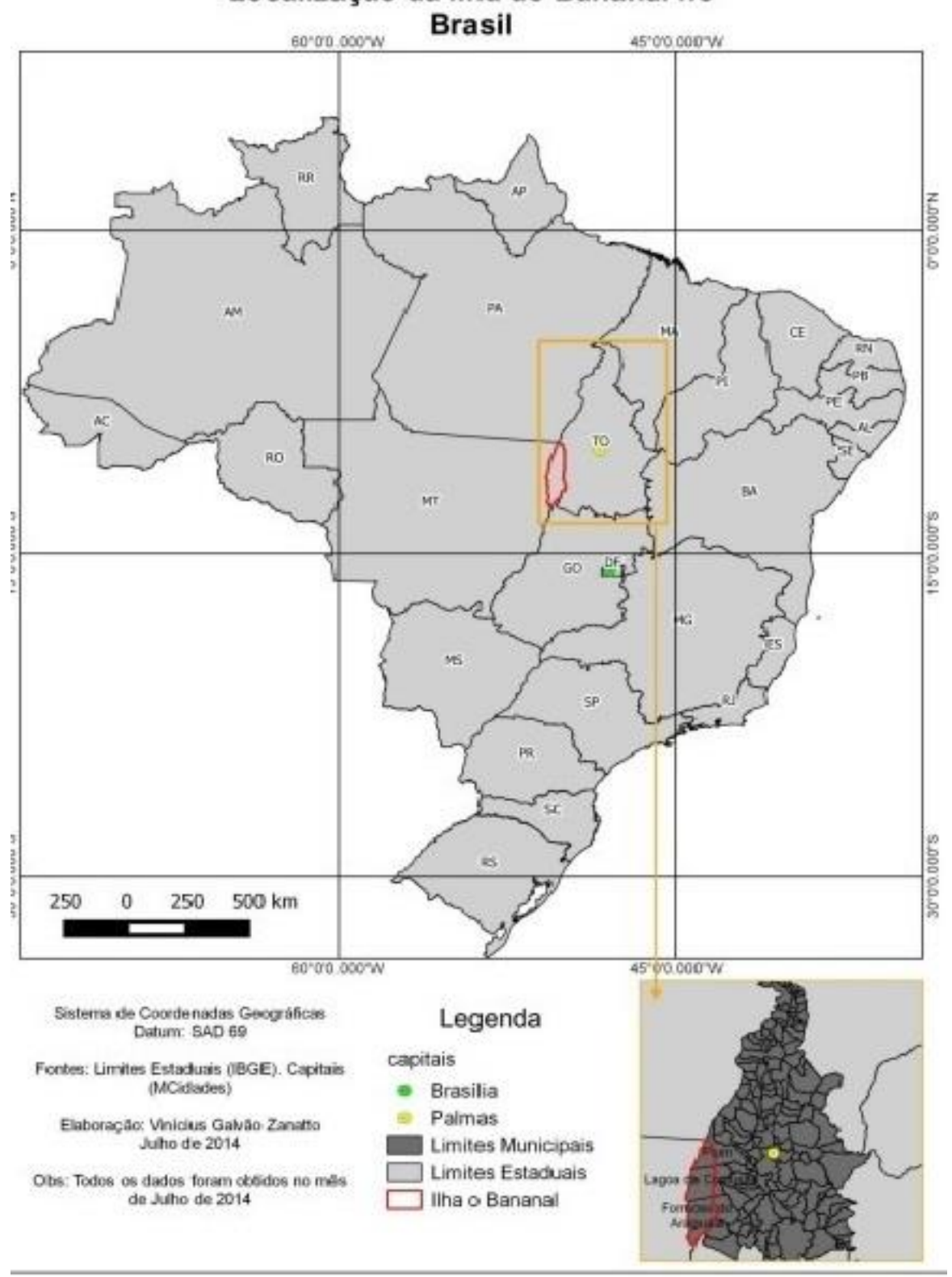

Fonte:f ile://C:/Users/Rodrigues/Documents/tcc/2014ViniciusGalvaoZanatto.pdf Acesso em: 05 abr. 2015.

A localização e a distribuição do povo Karajá no estado do Tocantins só foi registrada no Século XIX, como mostra Toral (1992):

(1) os Karajá meridionais, ou seja, ao sul da Ilha do Bananal,

(2) os de seu trecho médio, compreendido entre as barras dos rios das Mortes e Tapirapé' e

(3)osKarajá "setentrionais", quevivematualmenteaonortedabarra desse último rio até a atual Santana do Araguaia. Esses últimos não devem ser confundidos com os Karajá do Norte (TORAL, 1992, p. $35)$. 
O deslocamento de muitas famílias Iny para o sul do Tocantins foi provocado por conflitos internos entre famílias, facções e não indígenas. De acordo com Toral (1992, p. 18),

[...] em data muito anterior a 1500, parte considerável dessa população Karajá do baixo Araguaia passou progressivamente a se dirigir para o sul, desligando-se dos demais, e estabeleceu-se no seu médio curso, na altura da Ilha do Bananal. Passaram a se relacionar pacificamente com uma série de tribos de referência mítica, como os Kalatina, Besohoni, Hytè, Horue e Werè. A esse primeiro grupo de secessionistas, ascendentes dos atuais Javaé, seguiu-se, pouco tempo depois, uma segunda leva que se estabeleceu na região norte da Ilha: foram os ascendentes dos atuais Karajá. Progressivamente, os do norte da Ilha passaram a entrar em conflito com os da região central, terminando por expulsá-los e as tribos que se coligavam com eles, como os Were. Alguns Karajá dizem que os Were migraram para a região do atual Xingu; outros dizem que são os atuais Javaé (TORAL, 1992, p. 18).

Devido a esses conflitos, o povo Javaé (que também pertence ao mesmo povo Iny) passou a morar ao longo das margens do rio Javaé. Alguns relatos dizem que esse povo Javaé são os Werè, e os Karajá os reconhecem como um povo misturado, ou seja, Werè e Karajá, resultado dos casamentos interétnicos. O povo Javaé fala a língua Iny Rubè, com alguns dialetos diferenciados. Sobre essa formação sociocultural, Toral (1992, p. 36) afirma:

Os Werè, segundo os Karajá, são os mesmos Javaé que atualmente conhecemos e, ao mesmo tempo uma tribo que migrou para oeste, para a região do Xingu. É provável que sejam os mesmos Araé do rio das Mortes. Os Javaé, no entanto, chamam de Werè a um grupo indígenaque efetivamente "saiudebaixo daterra" (i.é, temseuponto de dispersão original) na região do Araguaia. Afirmam ainda que conviveram com os Werè e que deles aprenderam muitas coisas fundamentais, como grande parte das técnicas e conhecimentos xamanísticos. Mas, segundo os Javaé, os Werè são, definitivamente, outro grupo que não eles próprios (TORAL, 1992, p. 36).

Houve uma miscigenação de várias etnias por causa dos casamentos interétnicos. Assim, alguns indígenas se reconhecem como Werè, outros, como Javaé, outros, como Karajá, e outros, Karajá Javaé. Nesse contexto político e cultural, os Karajá, conhecidos como os Karajá da Ilha, formam outra comunidade de Iny, que reside na Ilha do Bananal, no município de Lagoa da Confusão - TO, em casas que margeiam o rio Araguaia. Esse povo também vive as faces da interculturalidade em seu dia a dia, seja em suas aldeias, em seu convívio com a população não indígena ou com outros povos indígenas. 
Ainda em relação aos povos Karajá, Javaé e Karajá de Xambioá, todos se alimentam à base de peixe e são considerados bons pescadores e mergulhadores. Também obtêm sua subsistência das roças de tocos e da produção de artesanato. São considerados os povos indígenas do Tocantins com uma vasta manifestação cultural e se expressam através de várias simbologias. Dentre elas, mencionamos as mais variadas pinturas corporais, a arte plumária dos raheto, as tradicionais festas de hetohok $\bar{y}^{-5}$, que é o rito de passagem dos jovens para a fase de homem. Há, também, o Ijadòma, o rito de passagem das meninas-moças quando da primeira menstruação. Elas são enfeitadas com lindos adornos para dançar com os aruanãs ${ }^{6}$. São esses e outros saberes que fazem parte da oralidade desse povo, que se renova a cada momento da vida do ser indígena Karajá ou do ser Iny.

\section{KARAJÁ XAMBIOÁ}

Devido à complexidade dos saberes dos Karajá, o foco desta pesquisa é somente o povo Karajá de Xambioá $^{7}$, pertencente a um dos mais de 180 grupos indígenas do Brasil. Esse povo apresenta diferenças consideráveis, que variam de acordo com o tronco linguístico ao qual sua língua está vinculada, às suas manifestações culturais, às práticas socioculturais e, em particular, à simbologia da pintura corporal de cada um desses povos. Assim são os Karajá de Xambioá:

Os Karajá do Norte, o mais setentrional dos três grupos da tribo Karajá, são tradicionais habitantes da região do baixo Araguaia. No Século XIX, quando surgem as primeiras notícias esclarecedoras sobre sua localização, encontravam-se definitivamente separados dos demais Karajá (apenas alguns bandos percorriam a região ao norte da ponta setentrional da Ilha) e das suas grandes aldeias (TORAL, 1992, p. 26).

O grupo Karajá de Xambioá também é denominado de Karajá do Norte. São conhecidos pelos Iny ${ }^{8}$ como Iraru Mahãdu (povo de baixo), falantes da língua Iny rubè (nossa fala, fala do povo Iny), pertencente à família linguística Karajá (tronco MacroJê). Os primeiros contatos do povo Karajá do Norte com os tori (não indígenas) remontam ao Século XVII, através do assalto de paulistas às suas comunidades, como destaca TORAL (1992).

\footnotetext{
${ }^{5}$ Significa casa grande.

${ }^{6}$ São espíritos dos antepassados.

${ }^{7}$ O povo Karajá de Xambioá também é conhecido como Karajá do Norte. Mas, neste estudo, quando não se trata de pesquisadas realizadas anteriormente, referimo-nos a ele como os Karajá de Xambioá.

${ }^{8}$ De acordo nossos informantes, Iny significa“"nós".
} 
Em dias atuais, o povo Karajá do Norte ou Karajá Xambioá se localiza nas terras indígenas à margem direita do rio Araguaia, no município de Santa Fé do Araguaia, a $70 \mathrm{~km}$ de Araguaína, ao norte do Tocantins (mapa 3). Os Karajá de Xambioá utilizam a palavra Xambioá para se autodenominar, apesar de não estarem localizados na cidade de Xambioá, nome que se origina do vocábulo ixybiowa (amigo do povo). Esses povos

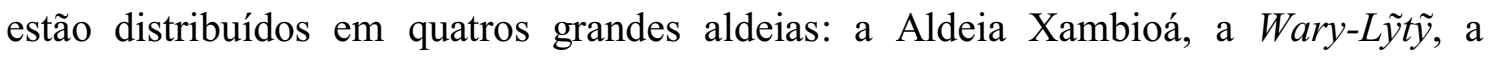
Kurehê e a Hawa-Tymara

Fonte 3: Mapa das terra indígena Karajá de Xambioá

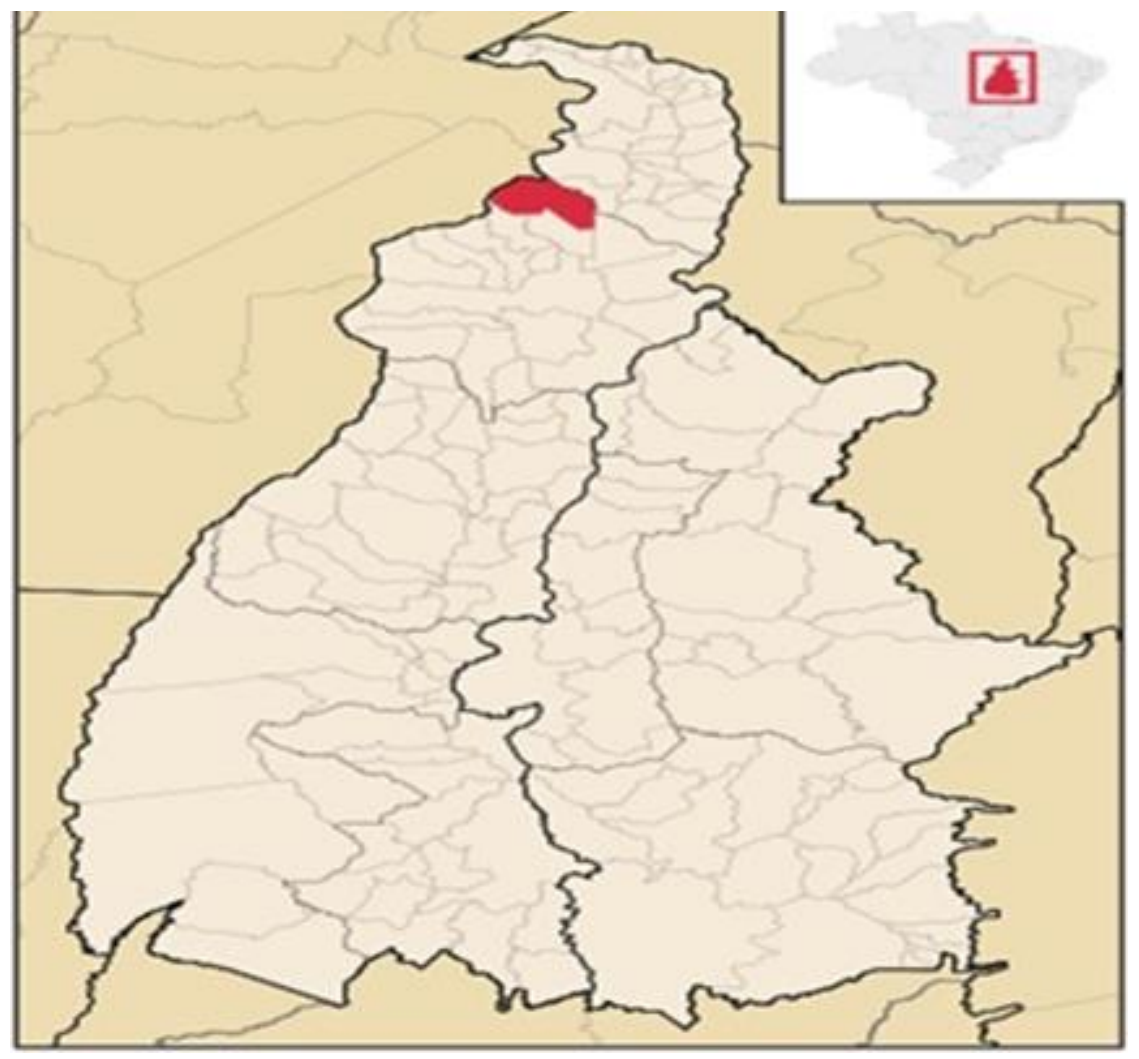

Fonte: http://www.mfrural.com.br/cidade/xambioa-to.aspx Acesso em: 15 dez. 2014.

Toral (1992) afirma que o povo Karajá de Xambioá habitava $240 \mathrm{~km}$ de percurso da margem direita do rio Araguaia e vivia com abundância de alimentação, principalmente de peixe. É considerado um povo simples, e a comunidade indígena foi formada de modo próspero. Entretanto, devido a vários problemas de origem externa à comunidade, principalmente o contato cada vez mais frequente com os não indígenas, a comunidade enfraqueceu-se linguisticamente. As práticas de manifestação cultural também perderam espaço e foram abandonadas com o tempo, o que ocasionou uma 
perda imensurável dos saberes tradicionais. Nesse contexto, Toral (1992) aponta algumas fases críticas que conduziram os Karajá de Xambioá a uma situação muito distinta culturalmente dos demais povos Karajá e Javaé:

A partir do final do Séc. XIX em diante, os efeitos dos choques com guarnições militaresdos “presídios"construídosnaregiãoparavigiá los e garantir a navegação, da repressão promovida por missionários capuchinhos aliados à violenta aparição de epidemias causaram o desmoronamento de sua população e uma mudança na composição dos grupos. Cerca de aproximadamente 2.000 pessoas em 1842 declinam para 1.350 em 1887, 60 em 1940 e 40 pessoas em 1959, o número mais baixo que jamais atingiram (TORAL, 1992, p. 26).

A diminuição da população Karajá foi ocasionada por várias situações conflituosas que viveu por longos anos. Dentre elas, podemos as várias emboscadas preparadas pelos invasores de distintas naturezas (como as de fazendeiros) e doenças (como malária, febre amarela e outras) que foram contraídas através do contato com o não indígena.

Em meio a esses conflitos, as poucas famílias Karajá de Xambioá se dividiram e passaram a habitar diferentes áreas da terra “indígena”. Assim, na década de 1940, o

Serviço de Proteção ao Índio - SPI - passou a atuar junto com esse povo, na tentativa de reuni-los em um único espaço físico e geográfico. Atualmente essa área está demarcada pelo Governo Federal, como área indígena Karajá Xambioá, ocorrida em meados do Século XX. O aumento populacional do povo em questão se deu por meio dos casamentos interétnicos, com indígenas de outras etnias (a maioria Guarani Mbyà) e com os não indígenas. Assim, esses migrantes contribuíram para aumentar a população Karajá. Toral (1992, p. 4) assevera que

[...] foi a incorporação dos regionais [não indígenas] e dos Guarani que permitiu a recuperação populacional, impedindo a extinção física na década de 1960, quando os Karajá do Norte foram reduzidos a apenas 40 pessoas, devido à irrupção violenta de diversos tipos de moléstias, alcoolismo e lutas internas (TORAL, 2001, p. 4).

Para Toral (1992, p. 31), a presença de não indígenas dentro das aldeias causou mudanças expressivas em seus costumes e tradições. Esse processo começou na década de 1970 e se estendeu até os dias atuais:

Do início de 1970 até 1982, foram contraídas 14 uniões com pessoas da região. Nessa última data viviam na aldeia nove regionais, cinco homens e quatro mulheres. Essas uniões com regionais explicam-se parcialmente em função da grande distância em relação às aldeias 
Karajá mais próximas (mais de 100 km rio “acima”, i.e., ao sul) e também devido às relações sempre tensas entre as famílias reunidas na aldeia "do Posto". Se por um lado essas uniões permitiram a recuperação populacional do grupo, por outro causaram considerável abalo na manutenção de certos aspectos da cultura Karajá do Norte. A vida ritual foi muito simplificada, restringindo-se, em 1982, à montagem de algumas fases da cerimônia de iniciação dos rapazes. A língua é falada, grosso modo, apenas pelos maiores de 15 anos. Os demais têm umarelação "passiva" coma língua: entendem, masnão falam. Mantiveram-se, no entanto, como uma comunidade discreta em meio aos núcleos regionais vizinhos, reconhecendo-se e fazendo questão de serem reconhecidoscomo "índios" e"Karajá."(TORAL, 2001, p. 31).

Essas mudanças socioculturais foram bastante expressivas, entretanto algumas práticas culturais desse povo ainda se mantêm, como os hábitos alimentares, à base de peixes e da captura de outros animais, como a tartaruga e a tracajá, e a cosmologia.

\section{A ETNOMATEMÁTICA E A FORMAÇÃO DOS PROFESSORES INDÍGENAS}

Todas as sociedades têm um modo particular de educar seus membros, por meio da oralidade e de suas tradições. Com esse viés, pode-se delinear um caminho para as ações educativas, com o fim de abrir as portas para um ensino que proporcione uma discussão atenciosa tanto para os grupos de minoria quanto para os povos tradicionais.

A educação intercultural é um meio para atender às escolas indígenas, de acordo com as inúmeras realidades dos povos tradicionais. A Etnomatemática está presente em ações educativas, por meio das quais os conhecimentos matemáticos podem ser assimilados no ambiente escolar indígena. Assim, os alunos podem produzir seus conhecimentos segundo seus fundamentos, que são relevantes em suas práticas socioculturais. Desse modo, reflexões e pesquisas relacionadas à formação de professores indígenas e a Etnomatemática se intensificam, visando harmonizar a sociedade não indígena e a cultura indígena.

Com a escola nos moldes ocidentais entrando nas aldeias como decorrência do contato com o outro, com os não-índios, a questão da interculturalidade, isto é, do conseguir fazer dialogar comportamentos e conhecimentos construídos sob base culturais distintas e frequentemente conflitantes é atualmente entendida como o esteio, a razão de ser da escola indígena. $O$ desafio posto pela interculturalidade não pode, nesse contexto, ser entendido como um "plus",comoumenriquecimento, como um bônus - como parece ser o caso na maior parte das escolas não-indígenas - porque $\mathrm{o}$ investimento no estabelecimento do diálogo, na capacidade de resolução do conflito intercultural é o alicerce, é o que justifica 
mesmo a existência dessa escola, é o que dá a ela relevância política (GRUPIONI, 2006, p. 27).

É necessário, no entanto, repensar a escola indígena de modo que ela possa preparar seus alunos para enfrentarem as possíveis dificuldades com a sociedade que os envolve e que, por vezes, é esquecida em relação aos direitos às crenças e às práticas socioculturais indígenas. Nesse contexto, a matemática escolar segui u como um campo de conhecimento que se relaciona delicadamente com o ambiente cultural onde esteja sendo produzida e transmitida.

Uma sociedade de 400 pessoas não pode se dar o luxo, por exemplo, de ver um de seus membros afirmar " ah, eu não quero aprender a pescar - euquero aprendersânscrito!’. Aprendersânscrito para quê? $\mathrm{O}$ conhecimento tem que ser útil para apenas um único indivíduo. Muito pelo contrário: valoriza-se aquisição de conhecimentos que sejam úteis para o bem - estar comunitário. E, além disso, o ensino não é uma responsabilidade de uma única pessoa, ele é responsabilidade de todos. Na Educação Indígena, não existe a figura do "professor". Sãováriosos “professores"dacriança.Amãeensina; ela é professora. Todo mundo é professor... e todo mundo é aluno. Não há, como em nossa sociedade, um único "detentor do saber" autorizado por uma instituição para educar as crianças e os jovens (GRUPIONI, 2006, p. 18).

No âmbito dessas discussões, a inserção da escola indígena como direito dos povos indígenas no território brasileiro, estabelecido pela Constituição de 1988 e otimizado no Referencial Curriculares Nacionais para as Escolas Indígenas de 1998 (BRASIL, 1998), estabelece que toda escola indígena seja bilíngue, específica, diferenciada e intercultural e se adéque a cada realidade, para facultar a melhor educação para os povos indígenas.

Por uma escola indígena especifica, diferenciada, intercultural bilingue e de qualidade, tornou-se, hoje, o moto daqueles que, renegando os modelos assimilacionistas, lutam pela implantação de programas de educação escolares que estejam a serviço das comunidades indígenas, e não contra elas. É claro que qualquer mudança de paradigmas leva tempo, não se faz do dia para a noite, pois isso não envolve apenas realinhamentos ideológicos, mudanças de discurso: é preciso, sobretudo, descobrir formas concretas para tornar o desejo efetivamente realidade. E para escapar das arapucas que o antigo paradigma insiste em nos armar... Temos muitos projetos de Educação Escolar Indígena no país envolvidos culturalmente sensíveis e politicamente relevantes para as comunidades indígenas. $\mathrm{O}$ primeiro passo para garantir a existência desse tipo de escola é que o condutor de todo o processo escolar seja, evidentemente, um professor indígena. Esse profissional, entende-se, seria o mais adequado para 
levar a cabo o projeto político-pedagógico de sua comunidade (GRUPIONI, 2006, p. 23).

Quando mencionamos os diálogos sobre a formação de professor indígena no seu contexto cultural específico e social, referimo-nos ao professor que identifica e compreende as distintas técnicas, que dizem respeito ao modo de conhecer, pensar, falar e viver desse grupo indígena. Desse modo, as experiências vivenciadas por esse professor indígena irão se refletir no desenvolvimento de ações educativas que abrangerão o contexto sociocultural e a matemática.

Durante o período da pesquisa de campo, realizada na aldeia indígena do povo Karajá Xambioá, utilizamos a técnica de abordagem de pesquisa, ou seja, uma entrevista não estruturada com um roteiro previamente estabelecido. Destacamos, dentre as falas do professor indígena, a importância de se trabalharem os saberes culturais indígenas na escola, dialogando com os conteúdos curriculares que foram mais enfatizados. Ele também relata que uma das maiores dificuldades para efetivar esse conhecimento é o livro didático disponibilizado para as escolas indígenas, porque não atende às necessidades da escola.

O professor indígena se propôs a desenvolver, nas aulas para os alunos indígenas dos anos iniciais, ações que pudessem transversalizar o contexto cultural e a matemática, para suprir essa carência em materiais didático-pedagógicos específicos. Dentre essas ações, estão o sistema numérico do povo indígena Karajá e a representação do cotidiano dos alunos, para desenvolver pontos conceituais da aritmética e dialogar com os saberes culturais e os científicos.

\section{CONSIDERAÇÕES FINAIS}

O trabalho empreendido não pretendeu esgotar a complexa realidade que envolve o povo Karajá de Xambioá, particularmente o ensino e aprendizagem de matemática. Contudo, foi uma tentativa de reforçar as discussões a respeito da educação escolar indígena e a formação do professor indígena, conforme referido neste texto.

Com as informações obtidas na comunidade indígena, constatou-se que a educação escolar vivencia sucessivas ações didáticas e pedagó gicas que permeiam a construção de uma educação diferenciada, intercultural e bilíngue/multilíngue. Uma dessas ações foram as aulas para os alunos indígenas dos anos iniciais do ensino fundamental, que dialoga com os saberes culturais indígenas e os sabere s científicos, em 
que foi apresentado o sistema numérico do povo indígena Karajá e desenvolvidos pontos conceituais da aritmética.

A Etnomatemática foi abordada, em seus aspectos teóricos e práticos, como um programa sobremaneira relevante, que ousa enfrentar alguns dos mais importantes problemas educacionais da atualidade, como a transdisciplinaridade, a globalização e o multiculturalismo. Procuram-se entender, por meio desse programa, as diferentes realidades com a utilização dos diversos métodos que os distintos povos desenvolvem para encontrar explicações para as situações-problema do cotidiano, com a finalidade de aumentar o entendimento do mundo, de acordo com o espaço e o tempo de cada cultura.

Dessa forma, acreditamos ser possível elaborar uma ação pedagógica intercultural por meio da qual o estudante seja estimulado a aprender, a pesquisar e a buscar sua cidadania mais próxima de sua realidade. O Programa Etnomatemática vem proporcionando distintas ferramentas para o educador de Matemática, quais sejam: repensar a atual conjuntura sociocultural de seus alunos, inovar seus métodos pedagógicos e oferecer meios para equilibrar os aprendizados dentro e fora do ambiente escolar, na perspectiva de que o educando assuma a responsabilidade pela própria aprendizagem.

O estudo etnomatemático parte do princípio de que não existe apenas uma matemática com caráter universal, civilizacional, mas diversas expressões matemáticas, que emergem em culturas particulares e únicas e em que se encontram sentidos para matematizar os saberes. Assim, considerando esse pressuposto, entende-se que, para ensinar matemática, é preciso contextualizar a aprendizagem nos quadros culturais, sociais e étnicos.

\begin{abstract}
This paper presents an investigation with the indigenous community Karajá Xambioá, located in Santa Fé do Araguaia TO. Using ethnographic methodology to collect data directly in the community through interviews and observation, about what the natives understand about the different indigenous education from the perspective of intercultural education, considering the socio-cultural aspects of their community. Aimed investigative study of educational reality of indigenous schools located in the territory Karajá Xambioá. Were analyzed among other things, the prominent need of teachers and the community to develop the schools of the village a study on the process of teaching and learning that seeks to take into account the mathematical produced in their cultural and social context.
\end{abstract}

Keywords: Transdisciplinary; Indigenous Education; Indian Teacher Training. 


\section{REFERÊNCIAS}

BRASIL. Ministério da Educação. Lei de Diretrizes e Bases da Educação Nacional, n 9.394 , de 20 de dezembro de 1996.

. Ministério da Educação. Plano Nacional de Educação. Brasília: MEC, 2001.

. Ministério da Educação. Referencial Curricular Nacional para a

Educação Escolar Indígena. Brasília: MEC/SEF, 1998.

D'AMBRÓSIO, Ubiratan. Educação matemática da teoria à prática. 13. ed. Campinas, SP: Papirus, 1996. 120 p.

D'AMBRÓSIO, Ubiratan. Etnomatemática: elo entre as tradições e a modernidade. 2. ed. Belo Horizonte: Autêntica, 2005. 110 p.

FERREIRA, Mariana Kawall Leal. Idéia matemática de povos culturalmente distintos. São Paulo: Global, 2002, p. 336.

GRUPIONI, Luís Donizete Benzi. Contextualizando o campo da formação de professores indígenas no Brasil. In: GRUPIONI, Luís Donizete Benzi. Formação de professores indígenas: repensando trajetórias. Brasília: Ministério da Educação, Secretaria de Educação Continuada, Alfabetização e Diversidade, 2006.

MONTEIRO, A.; POMPEU JR, G. A Matemática e os temas transversais. São Paulo: Moderna, 2001.

TORAL, ANDRÉ, A. Cosmologia e Sociedade Karajá. 1992. 280 f. Dissertação (Mestrado em Antropologia) - Pós-Graduação em Antropologia, Universidade Federal do Rio de Janeiro, Rio de Janeiro. 1992. 